\title{
EXPERIMENTAL STUDY ON BENDING BEHAVIOUR OF TRIANGULAR WEB PROFILE STEEL BEAM SECTION
}

\author{
Fatimah De'nan', Nor Salwani Hashim² \\ ${ }^{1}$ Senior Lecturer, ${ }^{2}$ Phd Student, School of Civil Engineering, Universiti Sains Malaysia, 14300 Nibong Tebal, Penang, \\ Malaysia,fatimahdenan@yahoo.com,wani_a02@yahoo.com
}

\begin{abstract}
A triangular web profile $\left(T_{R I} W P\right)$ steel section is a section made of two flanges connected to a slender web. The web and the flanges can be produced from different steel grades depending on design requirements. The flanges width and thickness is determined based on the depth of the section. The web is corrugated at regular interval into triangular shape along the length of the beam. This paper describes an experimental study on the bending behavior in major $\left(I_{x}\right)$ and minor $\left(I_{y}\right)$ axes of Triangular Web Profile $\left(T_{R I} W P\right)$ compared to flat web (FW) steel sections. Two types of sizing involved which is $200 \times 100 \times 6 \times 3 \mathrm{~mm}$ and $180 \times 75 \times 5 \times 2 \mathrm{~mm}$ section. Each of beam section was modeled using several spans such as $3 \mathrm{~m}, 4 \mathrm{~m}$ and $4.8 \mathrm{~m}$. It was observed that the $T_{R I} W P$ section had a higher stiffness about minor axis compared to that of $F W$ steel section but has lower stiffness about major axis. The analyses results show that the flexural stiffness for $T_{R I} W P 1$ is 0.794 times the $I_{x}$ of the flat web steel section (FW1). Meanwhile, the flexural stiffness for $T_{R I} W P 1$ is 1.429 times the $I_{y}$ of the flat web steel section ( $F W 1$. The findings for section $T_{R I} W P 2$ found to be similar to that of $T_{R I} W P 1$. For the section $T_{R I} W P 2$, it was observed that the value of $I_{x}$ of $T_{R I} W P$ is 0.780 times the $I_{x}$ of $F W$ steel section which is less than that of $F W$. The $I_{y}$ of $T_{R I} W P$ is 1.393 times the $I_{y}$ of FW steel section which is more than that of FW steel section.
\end{abstract}

Keywords: Flexural stiffness, Bending, Triangular web profile.

\section{INTRODUCTION}

This paper discusses the determination of the second moment of area on minor $\left(I_{y}\right)$ and major $\left(I_{x}\right)$ axes of a triangular web profile $\left(\mathrm{T}_{\mathrm{RI}} \mathrm{WP}\right)$ steel section (see Figure 1). The second moment of area values in major and minor axes can be easily calculated for a normal flat web (FW) plate girder. This is because the web is flat and uniform in profile throughout the length. For a $\mathrm{T}_{\mathrm{RI}} \mathrm{WP}$ steel section, the calculation of the second moment of area is difficult due to the corrugated shape of the web. The early studies have been done by Elgaaly which is concentrated on the vertically trapezoidal corrugation. He investigated the failure mechanisms of these beams under different loading modes such as bending mode, shear mode and compressive patch loads. It was found that the failure of beams under shear loading is due to local buckling on the web for coarse corrugation and global buckling on the web for dense corrugation (Elgaaly et al., 1996). They also found that the contribution of the web profile could be neglected in the calculation of the second moment of area of the TWP section, due to its insignificant contribution towards the beam loadcarrying capability (Elgaaly et al., 1997). However, it was found that the web might have a contribution towards increasing the second moment of area.

Nevertheless, under compressive patch loads, two distinct modes of failure observed. These involve the formation of collapse mechanism on flange followed by the web crippling or yielded web cripples followed by vertical bending of the flange into the crippled web. The failure of these beams is found to be dependent on the loading position and corrugation parameters where it can be a combination of the aforementioned modes (Elgaaly et al., 1997). Thus, further studies should be conducted to obtain a clearer understanding about this issue.

Besides that, the two distinct modes of failure under the effect of patch loading were dependent on the loading position and the corrugation parameters was investigated by Johnson and Cafolla (1997) and were further discussed in their writings. While, Luo and Edlund (1996) addressed the differences in results between an experimental and analytical analysis, was due to a consideration adopted in modeling. They found that the ultimate strength of a Ramberg-Osgood strain hardening model is $8-12 \%$ higher than an elastic-plastic model. About $7 \%$ reduction of ultimate load was contributed by the presence of local imperfection and global imperfection does not have much effect. While the corner effects due to cold forming has an insignificant effect on the ultimate strength. The ultimate strength is found to be $20 \%$ and $40 \%$ lower when a knife load was applied in comparison to uniform distributed patch load with patch length of 50 and $115.2 \mathrm{~mm}$, respectively. The highest value of strength obtained when the girder is loaded at the centre of the oblique part of corrugation and the lowest value was obtained at the centre of the flat part. Besides that, girders with larger corrugation angle and thicker web and 
flange have higher ultimate strength or ultimate shear capacity. In addition, the experimental tests conducted by Zhang et al. (2000) and Li et al. (2000) was found that the corrugated web beam has 1.5-2 times higher buckling resistance than the plane web beam.

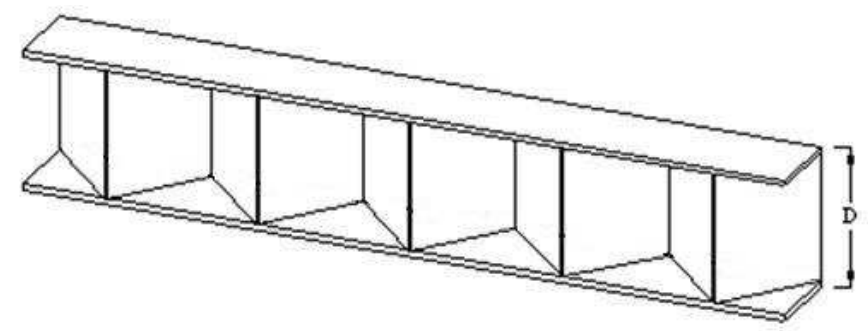

$T$ - flange thickness

$B$ - flange width

$t_{w}$ - web thickness

d-depth of web

$D$ - overall depth

(a) Isometric view

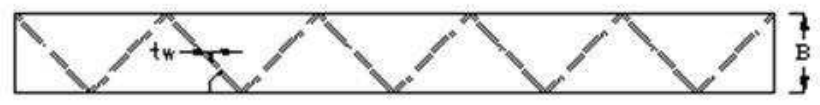

(b) Plan view
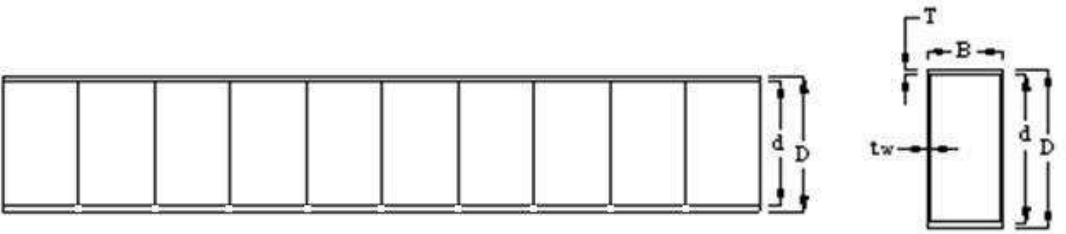

(c) Side view

(d) Section view

Fig -1: Shape and dimensions of a typical TRIWP section (all units are in $\mathrm{mm}$ )

In order to use corrugated plates in the webs of the I-girder, it is important to understand the flexural and torsional behaviors of the I-girder with corrugated webs. However, studies on such behaviors are scarce. In particular, despite the importance of lateral-torsional buckling, it has been addressed by SayedAhmad (2005) and Moon (2009) in their papers.

Abbas et al. (2006) developed a theoretical formulation of the linear elastic in-plane and torsional behavior of corrugated web I-girders under in-plane loads and further theoretical, experimental, and finite element analysis results for the linear elastic behavior of corrugated web I-girders under primary bending moment and shear, focusing primarily on the phenomenon of transverse flange bending Abbas et al. (2007).

However, steel beam with corrugated web such as trapezoidal web have been widely used in recent years. Therefore, a new type of steel section namely triangular web profile $\left(\mathrm{T}_{\mathrm{RI}} \mathrm{WP}\right)$ will be studied in this paper to know the significant effect to bending behaviour as the transverse stiffeners will be eliminate and slanting stiffeners will be introduce in $\mathrm{T}_{\mathrm{RI}} \mathrm{WP}$ steel section.

\section{THEORY}

When a point load, $P$, is applied at the mid span of a simply supported beam, the maximum deflection, $\delta_{\max }$ for elastic condition, of the span can be calculated as:

$$
\delta_{\max }=\frac{P L^{3}}{48 E I}
$$

Where,

$I=$ second moment of area

$P=$ applied point load

$L=$ span of beam

$E=$ elastic modulus of steel

$\delta=$ vertical deflection at mid span

A linear relationship between the load $(P)$ versus deflection $(\delta)$ graph will represent the value of constant containing I. Since the length $(L)$ and Young Modulus $(E)$ for all models are known, the $I$ value for the $\mathrm{T}_{\mathrm{RI}} \mathrm{WP}$ steel section can be obtained from the slope of $\mathrm{P}-\delta$ plot obtained from experimental study. If two beams with the same material and length, the ratio of their moments of inertia, $\mathrm{I}_{1}$ and $\mathrm{I}_{2}$, will lead to (rearranging the Equation 1): 


$$
I_{1}=\frac{\left(\frac{P}{\delta}\right)_{1}}{\left(\frac{P}{\delta}\right)_{2}} \times I_{2}
$$

Thus, if finite element analysis for the $\mathrm{T}_{\mathrm{RI}} \mathrm{WP}$ and $\mathrm{FW}$ steel sections are performed, the second moment of area, $I$, for a $\mathrm{T}_{\mathrm{RI}} \mathrm{WP}$ section about any axis can be determined provided the second moment of area, $I$, of FW section of that axis is known, using Equation 3.

$$
I_{T_{R I} W P}=\frac{\left(\frac{P}{\delta}\right)_{T_{R I} W P}}{\left(\frac{P}{\delta}\right)_{F W}} \times I_{F W}
$$

The values of the flexural stiffness $(P / \delta)$ for the corrugated steel section such as trapezoidal web profile, $\mathrm{T}_{\mathrm{RI}} \mathrm{WP}$ and $\mathrm{FW}$ sections can be obtained from the $P-\delta$ graphs plotted from appropriate bending analysis.

\section{EXPERIMENTAL STUDY}

\subsection{Introduction}

The detail dimensions of the test specimens are given in Table 1. The load deflections results were then used to obtain the $I_{x}$ and $I_{y}$ value of the $\mathrm{T}_{\mathrm{RI}} \mathrm{WP}$ steel sections.

\subsection{Bending Test Equipment and Set-Up}

The specimen was laid down about major axis with the web facing up for the $I_{x}$ bending (see Figure 2). All type of specimens was simply supported at both ends. The beam is restrained from moving sideways to make sure that the beam undergoes a vertical bending. This is to make sure that the test was carried out in bending only without any lateral torsional buckling effects. Five vertical displacement transducers labelled as LVDT1, LVDT2, LVDT3, LVDT4 and LVDT5 respectively were located under the bottom flange. LVDT3 was placed at the centre of the specimen, which is below the loading point. As a guide to make sure the loading applied at centre position, LVDT2 and LVDT4 were located $300 \mathrm{~mm}$ from LVDT2, and LVDT1 and LVDT5 was placed $180 \mathrm{~mm}$ from each end. Figure 3 and Figure 4 show the actual conditions of the test for FW2 and $\mathrm{T}_{\mathrm{RI}} \mathrm{WP} 2$ steel section in minor and major axis, respectively. The loading process was monitored using a load cell placed under the hydraulic jack and all data were collected and recorded by data logger.

\begin{tabular}{|c|c|c|}
\hline \multicolumn{2}{|c|}{ Case } & Type of \\
\hline FW1 & \multirow{2}{*}{$\mathrm{L}=3 \mathrm{~m}, 4 \mathrm{~m}, 4.8 \mathrm{~m}$} & \\
\hline $200 \times 100 \times 6 \times 3 \mathrm{~mm}$ & & \\
\hline $\mathrm{T}_{\mathrm{RI}} \mathrm{WP} 1$ & \multirow{2}{*}{$\mathrm{L}=3 \mathrm{~m}, 4 \mathrm{~m}, 4.8 \mathrm{~m}$} & \\
\hline $200 \times 100 \times 6 \times 3 \mathrm{~mm}$ & & \\
\hline FW2 & \multirow{2}{*}{$\mathrm{L}=3 \mathrm{~m}, 4 \mathrm{~m}, 4.8 \mathrm{~m}$} & \\
\hline $180 \times 75 \times 5 \times 2 \mathrm{~mm}$ & & \\
\hline $\mathrm{T}_{\mathrm{RI}} \mathrm{WP} 2$ & \multirow{2}{*}{$\mathrm{L}=3 \mathrm{~m}, 4 \mathrm{~m}, 4.8 \mathrm{~m}$} & \\
\hline $180 \times 75 \times 5 \times 2 \mathrm{~mm}$ & & \\
\hline
\end{tabular}

Table -1: Dimensions of $\mathrm{T}_{\mathrm{RI}} \mathrm{WP}$ and FW steel section specimens 


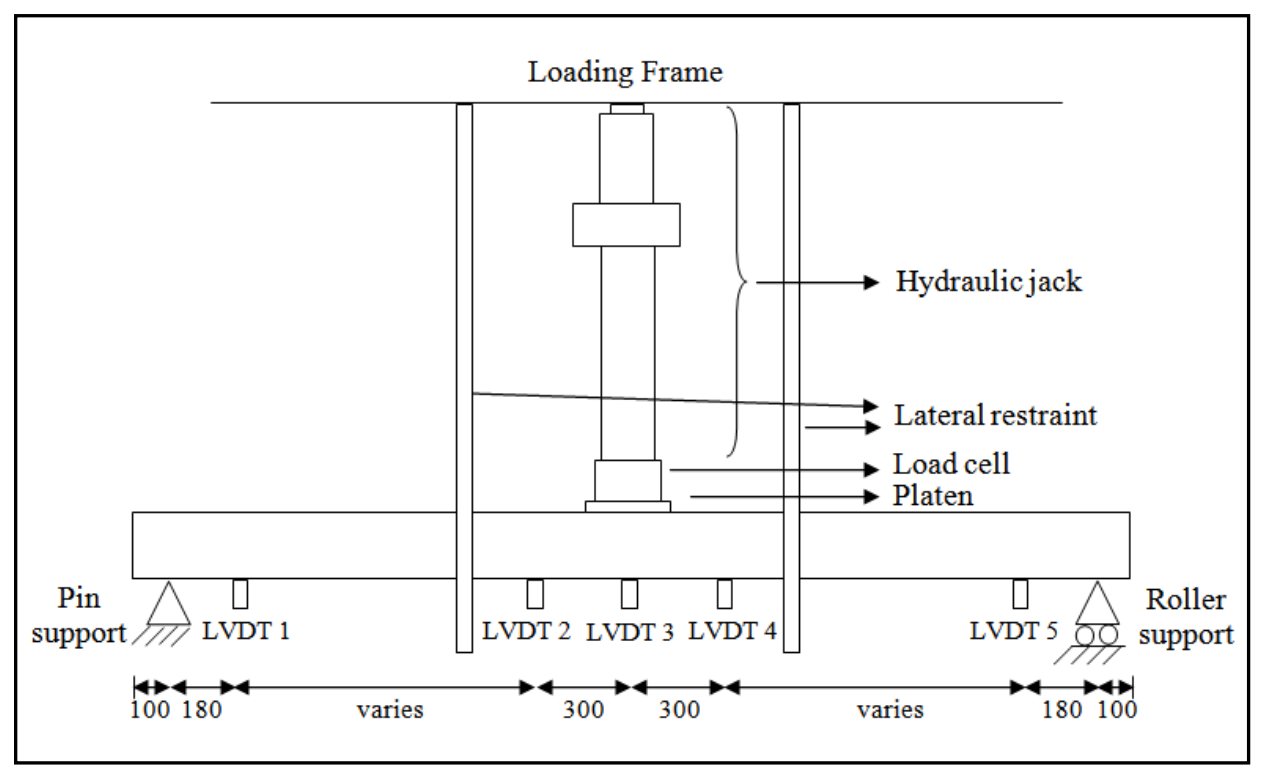

Fig -2: The test instrument arrangement

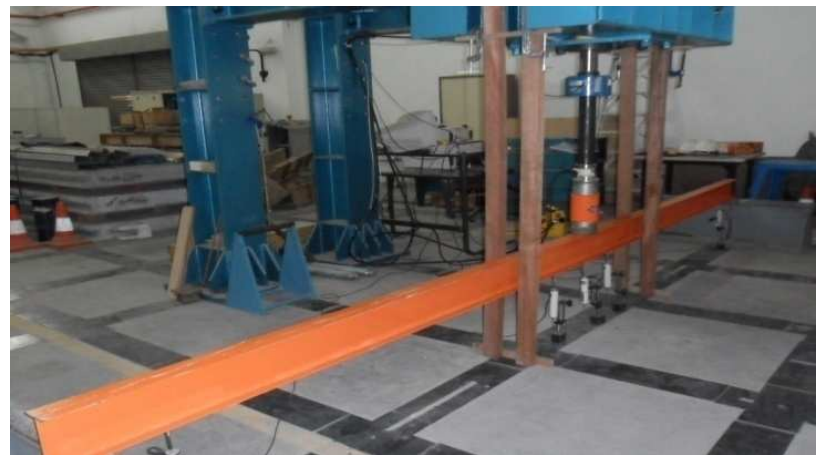

(a) Specimen under bending about major axis

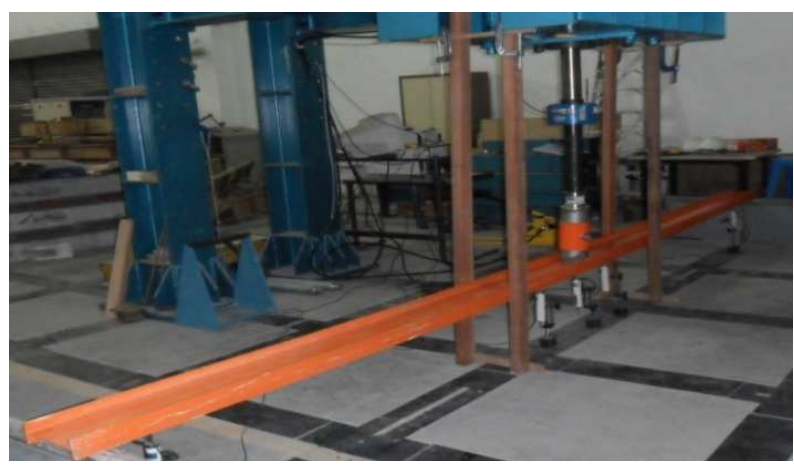

(b) Specimen under bending about minor axis

Fig -3: The actual test set up (FW1-Section $200 \times 100 \times 6 \times 3$ $\mathrm{mm})$

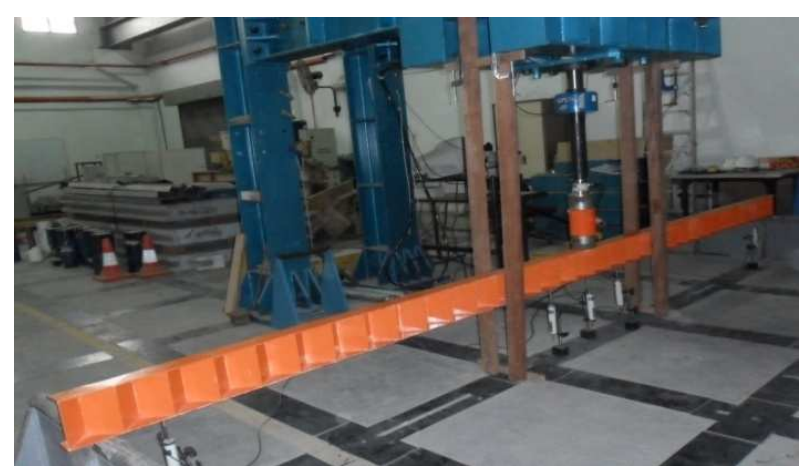

(a) Specimen under bending about major axis

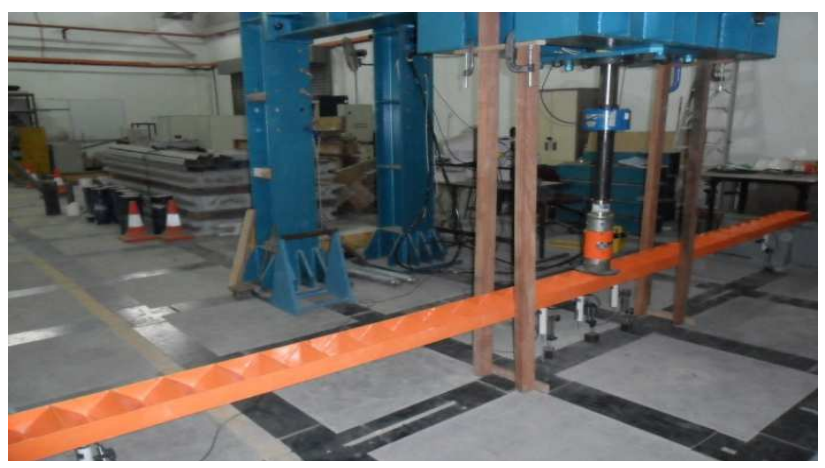

(b) Specimen under bending about minor axis

Fig -4: The actual test set up $\left(\mathrm{T}_{\mathrm{RI}} \mathrm{WP1}\right.$-Section $\left.200 \times 100 \times 6 \times 3 \mathrm{~mm}\right)$ 


\subsection{Test Procedures}

Bending tests were performed in different ranges of span such as $3000 \mathrm{~mm}, 4000 \mathrm{~mm}$ and $4800 \mathrm{~mm}$. The initial span of the beam was $3000 \mathrm{~mm}$. As the load $P$ was increased, the corresponding deflections at LVDT3 were recorded. The readings of vertical deflection at LVDT2 and LVDT4 were taken to act as a control, to ensure that the position of the point load, $P$, was at mid span. Meanwhile, LVDT 1 and LVDT 5 are to ensure that no deflection occurs near the end of the span. After the deflection data was recorded, the supports were adjusted to $4000 \mathrm{~mm}$ span respectively, and the same procedure was carried out for $4800 \mathrm{~mm}$ span as shown in Figure 5. By using the data logger, the reading of vertical deflection was first set to zero. At every load level, the reading of vertical deflection was recorded. The test was stopped at $1 / 3$ of design moment capacity before the elastic capacity of the specimen was exceeded. The load applied was at the centre of the beam (concentrated load), and the vertical deflection of beam specimens were measured at mid span (LVDT3). The deflection of LVDT2 and LVDT4, and LVDT1 and LVDT5 are found to be almost the same.

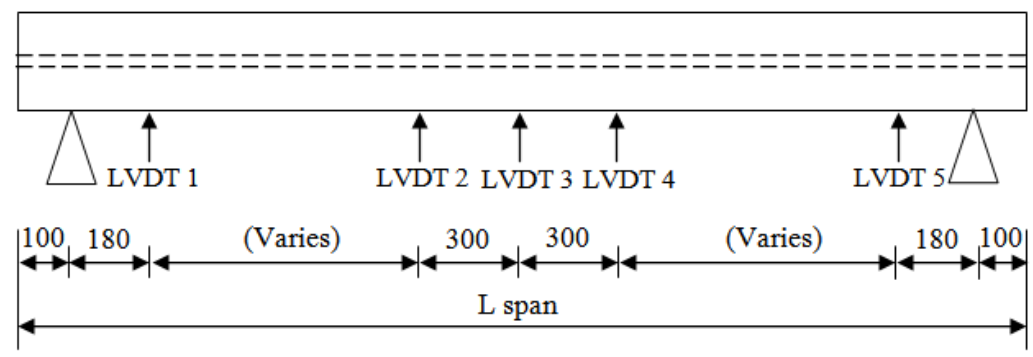

Fig -5: The position of LVDTs for the bending test (all units in $\mathrm{mm}$ )

\section{RESULTS AND DISCUSSION}

The maximum deflection results of experimental study for FW and $\mathrm{T}_{\mathrm{RI}} \mathrm{WP}$ steel section are summarized in Table 2 and Table 3. In this study, the deflections about major axis for $\mathrm{T}_{\mathrm{RI}} \mathrm{WP}$ steel section is more than that of FW steel section (Table 2(a) and Table 3(a)). However, deflection about minor axis for $\mathrm{T}_{\mathrm{RI}} \mathrm{WP}$ steel section is less than FW steel section as summarized in Table 2(b) and Table 3(b). It means that the $\mathrm{T}_{\mathrm{RI}} \mathrm{WP}$ steel section is stiffer compared to $\mathrm{FW}$ steel section about minor axis. In other word, $\mathrm{T}_{\mathrm{RI}} \mathrm{WP}$ steel section has a higher resistance to bending about minor axis than FW steel section.

Table -2: Deflections for $\mathrm{T}_{\mathrm{RI}} \mathrm{WP} 1$ and FW1 steel section (Section $200 \times 100 \times 6 \times 3$ )

(a) Point load $14 \mathrm{kN}$ about major axis

\begin{tabular}{|c|c|c|c|}
\hline $\begin{array}{c}\text { Span } \\
(\mathrm{mm})\end{array}$ & $\begin{array}{c}\delta_{T_{R I} W P} \\
(\mathrm{~mm})\end{array}$ & $\begin{array}{c}\delta_{F W} \\
(\mathrm{~mm})\end{array}$ & $\begin{array}{c}\delta_{T H E O R Y} \\
(\mathrm{~mm}) \\
\text { Equation 1 }\end{array}$ \\
\hline 3000 & 4.403 & 3.088 & 2.908 \\
\hline 4000 & 8.806 & 6.924 & 6.894 \\
\hline 4800 & 14.616 & 13.100 & 11.913 \\
\hline
\end{tabular}

(b) Point load $3 \mathrm{kN}$ about minor axis

\begin{tabular}{|c|c|c|c|}
\hline $\begin{array}{c}\text { Span } \\
(\mathrm{mm})\end{array}$ & $\begin{array}{c}\delta_{T_{R I} W P} \\
(\mathrm{~mm})\end{array}$ & $\begin{array}{c}\delta_{F W} \\
(\mathrm{~mm})\end{array}$ & $\begin{array}{c}\delta_{\text {THEORY }} \\
(\mathrm{mm}) \\
\text { Equation } 1\end{array}$ \\
\hline 3000 & 5.536 & 8.057 & 8.071 \\
\hline 4000 & 12.789 & 17.283 & 19.130 \\
\hline 4800 & 22.015 & 32.776 & 33.060 \\
\hline
\end{tabular}

Table -3: Deflections for $\mathrm{T}_{\mathrm{RI}} \mathrm{WP} 2$ and FW2 (Section $180 \times 75 \times 5 \times 2$ )

(a) Point load $8 \mathrm{kN}$ about major axis

\begin{tabular}{|c|c|c|c|}
\hline $\begin{array}{c}\text { Span } \\
(\mathrm{mm})\end{array}$ & $\begin{array}{c}\delta_{T_{R I} W P} \\
(\mathrm{~mm})\end{array}$ & $\begin{array}{c}\delta_{F W} \\
(\mathrm{~mm})\end{array}$ & $\begin{array}{c}\delta_{\text {THEORY }} \\
(\mathrm{mm}) \\
\text { Equation 1 }\end{array}$ \\
\hline 3000 & 4.951 & 3.636 & 3.281 \\
\hline 4000 & 9.811 & 7.856 & 7.777 \\
\hline 4800 & 16.754 & 13.502 & 13.440 \\
\hline
\end{tabular}

(b) Point load $1 \mathrm{kN}$ about minor axis

\begin{tabular}{|c|c|c|c|}
\hline $\begin{array}{c}\text { Span } \\
(\mathrm{mm})\end{array}$ & $\begin{array}{c}\delta_{T_{R I} W P} \\
(\mathrm{~mm})\end{array}$ & $\begin{array}{c}\delta_{F W} \\
(\mathrm{~mm})\end{array}$ & $\begin{array}{c}\delta_{\text {THEORY }} \\
(\mathrm{mm}) \\
\text { Equation } 1\end{array}$ \\
\hline 3000 & 5.280 & 7.710 & 7.654 \\
\hline 4000 & 14.452 & 18.343 & 18.140 \\
\hline 4800 & 21.230 & 30.858 & 31.346 \\
\hline
\end{tabular}


Table 4 and Table 5 show the flexural stiffness results about major and minor axis respectively for $\mathrm{T}_{\mathrm{RI}} \mathrm{WP}$ steel section compared to $\mathrm{FW}$ steel section for both sizes. The analyses result show that the flexural stiffness for $\mathrm{T}_{\mathrm{RI}} \mathrm{WP} 1$ is 0.794 times the $I_{x}$ of the flat web steel section (FW1) (see Table 4). Meanwhile, the flexural stiffness for $\mathrm{T}_{\mathrm{RI}} \mathrm{WP} 1$ is 1.429 times the $I_{y}$ of the flat web steel section (FW1) (see Table 4).
The findings for section $\mathrm{T}_{\mathrm{RI}} \mathrm{WP} 2$ found to be similar to that of $\mathrm{T}_{\mathrm{RI}} \mathrm{WP} 1$. For the section $\mathrm{T}_{\mathrm{RI}} \mathrm{WP} 2$, it was observed that the value of $I_{x}$ of $\mathrm{T}_{\mathrm{RI}} \mathrm{WP}$ is 0.780 times the $I_{x}$ of $\mathrm{FW}$ steel section which is less than that of FW (see Table 5). The $I_{y}$ of $\mathrm{T}_{\mathrm{RI}} \mathrm{WP}$ is 1.393 times the $I_{y}$ of FW steel section which is more than that of FW steel section (see Table 5).

Table 4: Percentage differences of flexural stiffness for $T_{R I} W P 1$ and FW1 steel section (Section $200 \times 100 \times 6 \times 3$ )

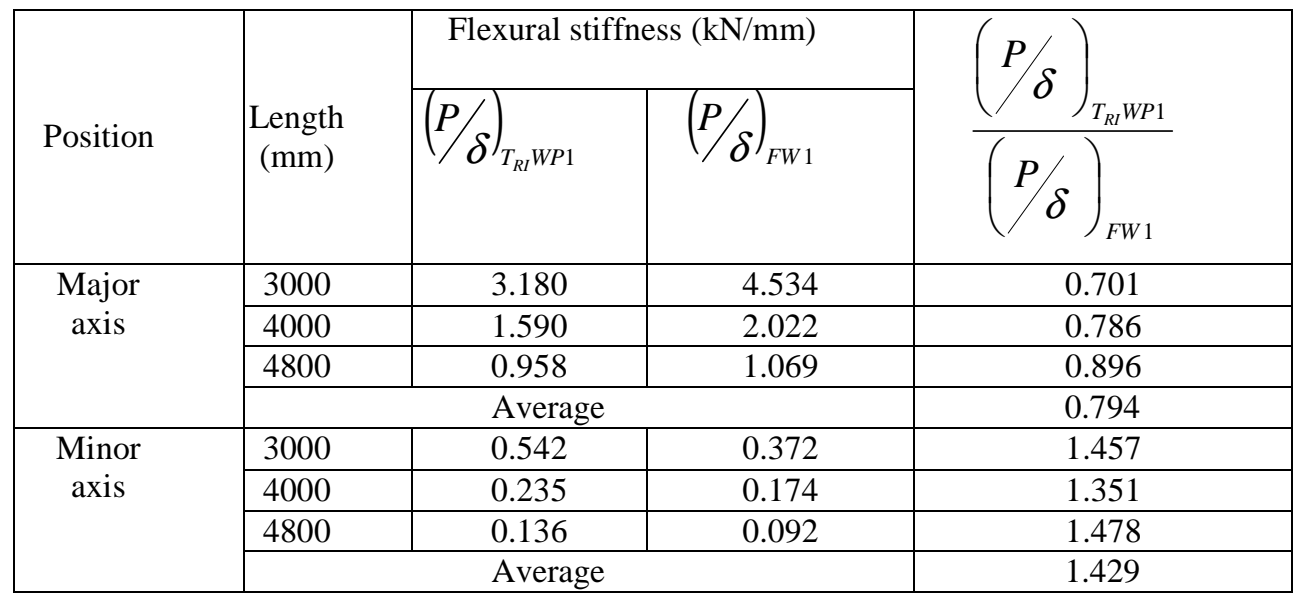

Table 5: Percentage differences of flexural stiffness for $T_{R I} W P 2$ and FW2 steel section $($ Section $180 \times 75 \times 5 \times 2)$

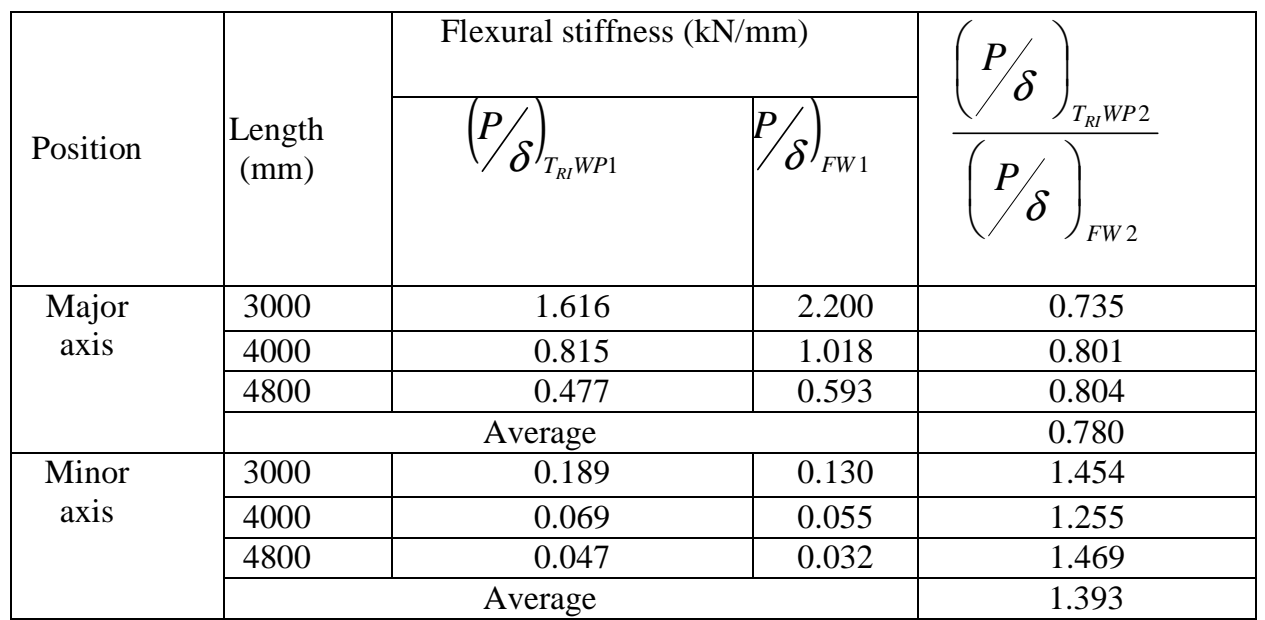

In summary, the deflection about minor axis for $\mathrm{T}_{\mathrm{RI}} \mathrm{WP}$ for both sizes is less than FW steel section. It means that the $\mathrm{T}_{\mathrm{RI}} \mathrm{WP}$ steel section is stiffer compared to $\mathrm{FW}$ steel section about minor axis. While the deflections about major axis for $\mathrm{T}_{\mathrm{RI}} \mathrm{WP}$ is more than that of FW steel section.

\section{CONCLUSIONS}

Therefore, this study is reliable for investigating the bending behavior about minor and major axis. The laboratory testing results indicated that the deflection about minor axis for $\mathrm{T}_{\mathrm{RI}} \mathrm{WP}$ steel section is less than FW. It means the $\mathrm{T}_{\mathrm{RI}} \mathrm{WP}$ steel section is stiffer compared to $\mathrm{FW}$ steel section about minor axis. In this regard, $\mathrm{T}_{\mathrm{RI}} \mathrm{WP}$ steel section has a higher resistance 
to bending about minor axis than FW steel section. Meanwhile, the deflections about major axis for $\mathrm{T}_{\mathrm{RI}} \mathrm{WP}$ steel section is more than that of FW steel section. It means that the $\mathrm{FW}$ is stiffer than $\mathrm{T}_{\mathrm{RI}} \mathrm{WP}$ steel section about major axis. It can be concluded that the introduction of slanting stiffeners shows higher resistance in bending behavior compare to that of corrugated section by using trapezoidal web.

\section{ACKNOWLEDGEMENTS}

The authors gratefully acknowledge the financial support of Universiti Sains Malaysia (USM), and the technical assistance support of Civil Engineering Lab Technician during the course of the research. This research was also made possible by the Short Term Grant (Account Number: 304/PAWAM/60312007) provided by the Universiti Sains Malaysia.

\section{REFERENCES}

[1]. Elgaaly, M., Hamilton, R. W. \& Seshadri, A. (1996). Shear Strength of Beams with Corrugated Webs. Journal of Structural Engineering, Vol. 122, pp.390398.

[2]. Elgaaly, M., Seshadri, A. \& Hamilton, R. W. (1997). Bending Strength of Steel Beams with Corrugated Webs. Journal of Structural Engineering, Vol. 123, pp.772-782.

[3]. Elgaaly, M. \& Seshadri, A. (1997). Girders with Corrugated Webs under Partial Compressive Edge Loading. Journal of Structural Engineering, Vol. 123, pp.783-791.

[4]. Elgaaly, M. \& Seshadri, A. (1998). Depicting the behavior of girders with corrugated webs up to failure using non-linear finite element analysis. Advances in Engineering Software, Vol. 29, pp.195-208.

[5]. Johnson, R. P. \& Cafolla, J. (1997). Local flange buckling in plate girders with corrugated webs. Proceedings of the Institution of Civil Engineers: Structures and Buildings, Vol. 122, pp.148-156.

[6]. Johnson, R. P. \& Cafolla, J. (1997). Corrugated webs in plate girders for bridges. Proceedings of the Institution of Civil Engineers: Structures and Buildings, Vol. 122, pp.157-164.

[7]. Luo, R. \& Edlund, B. (1996). Ultimate strength of girders with trapezoidally corrugated webs under patch loading. Thin-Walled Structures, Vol. 24, pp.135-156.

[8]. Luo, R. \& Edlund, B. (1996). Shear capacity of plate girders with trapezoidally corrugated webs. ThinWalled Structures, Vol. 26, pp.19-44.

[9]. Li Y, Zhang W, Zhou Q, Qi X, Widera GEO. (2000) Buckling strength analysis of the web of a WCW Hbeam: Part 2. Development and research on H-beams with wholly corrugated webs (WCW). Journal of Materials Processing Technology, Vol. 101(1), pp. 115-118.
[10]. Chan, C. L., Khalid, Y. A., Sahari, B. B. \& Hamouda, A. M. S. (2002). Finite element analysis of corrugated web beams under bending. Journal of Constructional Steel Research, Vol. 58, pp.1391-1406.

[11]. Khalid, Y. A., Chan, C. L., Sahari, B. B. \& Hamouda, A. M. S. (2004). Bending behaviour of corrugated web beams. Journal of Materials Processing Technology, Vol. 150, pp.242-254.

[12]. Sayed-Ahmed, E. Y. (2005). Lateral torsion-flexure buckling of corrugated web steel girders. Proceedings of the Institution of Civil Engineers: Structures and Buildings, Vol. 158, pp.53-69.

[13]. Moon, J., Yi, J.-W., Choi, B. H. \& Lee, H.-E. (2009). Lateral-torsional buckling of I-girder with corrugated webs under uniform bending. Thin-Walled Structures, Vol. 47, pp.21-30.

[14]. Abbas, H. H., Sause, R., and Driver, R. G. (2006). Behavior of corrugated web I-girders under in-plane loads. Journal of Engineering Mechanics, Vol. 132(8), pp.806-814.

[15]. Abbas, H. H., Sause, R., and Driver, R. G. (2007). Analysis of Flange Tranverse Bending of Corrugated Web I-Girders under In Plane Loads. Journal of Structural Engineering, Vol. 132(8), pp. 806-814.

[16]. Zhang W, Zhou Q, Li Y, Cai Z, Widera GEO. (2000) Hot rolling technique and profile design of tooth-shape rolls. Part 1: Development and research on H-beams with wholly corrugated webs. Journal of Materials Processing Technology, Vol. 101(1), pp. 110-114.

[17]. Zhang W, Li Y, Zhou Q, Qi X, Widera GEO. (2000) Optimization of the structure of an H-beam with either a flat or a corrugated web. Part 3: Development and research on H-beams with wholly corrugated webs. Journal of Materials Processing Technology, Vol. 101(1), pp.119-23.

\section{BIOGRAPHIES}

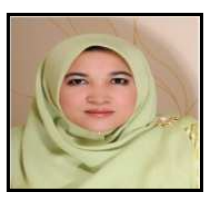

Dr Fatimah De'nan, B.Tech \& Ed. (Civil Eng), MSc (Structural Eng.), PhD (Civil EngSteel Structure) is a Senior Lecturer at the School of Civil Engineering, Universiti Sains Malaysia since 2008.

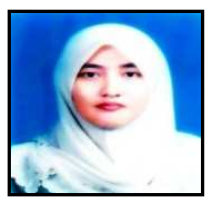

Nor Salwani Hashim, B. Eng. (Hon.) (Civil Eng.), MSc (Civil Eng.) is a PhD student cum Research Assistant at School of Civil Engineering, Universiti Sains Malaysia. 